\title{
Chronic and unexplained cough
}

\author{
Alessandro Zanasi ${ }^{1}$ \\ Massimiliano Mazzolini² \\ Carla Maria Sofia lerna ${ }^{2}$ \\ Matteo Alemanni ${ }^{3}$ \\ ${ }^{1}$ Italian association for cough study, Bologna, Italy \\ 2 Pneumology and Respiratory Intensive Care Unit, S. \\ Orsola Malpighi, Bologna, Italy \\ ${ }^{3}$ Italian Society of Clinical Pharmacy, Cagliari, Italy
}

\author{
Address for correspondence: \\ Alessandro Zanasi, MD \\ U.O. Pneumologia e UTIR \\ Policlinico S.Orsola-Malpighi \\ Via Albertoni 15 \\ 40138 Bologna, Italia \\ E-mail: alessandro.zanasi@aosp.bo.it
}

\section{Summary}

Cough is a frequent symptom reported in general practice consults. Even though most of the cases concern acute and self limiting episodes, if cough persists a comprehensive diagnostic evaluation should be started. Patients that scarcely respond to empiric therapy or whose symptoms are not clearly referable to one of the most common causes of cough may receive the diagnosis of unexplained cough. These patients frequently develop depression or social retirement. Recent studies have suggested that hypersensitivity of the cough reflex could be the pathogenic mechanism underlying unexplained cough. However hypersensitivity syndrome should not be used as an easy way out for patients with a complicated history of cough. Through our paper we will briefly review the most common causes of cough and how they could be involved in the development of hypersensitivity cough syndrome.

KEY WORDS: chronic cough; hypersensitivity syndrome; idiopathic cough; unexplained cough.

\section{Introduction}

On one hand cough represents a primary defensive mechanism of the airways. It prevents inhalation and aspiration of harmful gasses and particles from the environment and helps the mucous clearance from the low- er respiratory tract. On the other hand cough is one of the most frequent reasons for medical consult (1). The classification of cough as symptom is based firstly on its duration. Acute uncomplicated cough is usually self limiting in less than three weeks and in most of the cas-
Although the management of acute cough can require more than one visit, the impact on patient's quality of life is limited if compared to chronic cough. es it is imputable to upper airways viral infections (2). Although the management of acute cough can require more than one visit, the impact on patient's quality of life is limited if compared to chronic cough. When cough lasts for more than 8 weeks it is considered chronic cough. The chronic cough represents a larger and more important problem in terms of medical and economical burden because it frequently leads patients to seek medical attentions due to the concern raised by the persistence of the symptom (3). In early 1980 s the first cough diagnostic protocols appeared (4). The implementation of a diagnostic protocol showed significant improvements in diagnosis and treatment of cough, but some cases still miss a recognized cause (5). In this way patients with persistent and refractory cough frequently receive a diagnosis of idiopathic cough (6), it's known that the unresponsive patients may exceed $20 \%$ of cases (7) (Table 1). Several authors consider inappropriate to use the term "idiopathic" as long as a deep diagnostic assessment has not been completed (14). The persistence of cough can worsen both clinical and psychological condition of the patient, because a long history of unexplained chronic cough often entails poor quality of life, compromised social life and depression (15).

\section{Assessment of the etiology of chronic cough}

The evaluation of chronic cough usually starts with a general practitioner visit. If patients seek only a symptomatic treatment it is up to the physician to remark the importance of an appropriate clinical evaluation. When approaching a patient reporting chronic cough is mandatory to carefully follow a validated diagnostic protocol, as the one proposed in the American College of Chest Physicians (ACCP) guidelines for diagnosis of cough (16). In patients with history of chronic cough of unknown etiology the most common causes (Figure 1) are asthma, gastroesophageal reflux (GER) and upper airways cough syndrome (UACS). When the physical examination and the chest radiography are not significative, efforts should be aimed toward an appropriate and complete evaluation of these conditions (17). 
Table 1 - Most common cause of chronic cough.

\begin{tabular}{llllll}
\hline & $\begin{array}{l}\text { Number } \\
\text { of participants }\end{array}$ & $\begin{array}{l}\text { Asthma/CVA } \\
\text { EB/AC }\end{array}$ & GER & UACS & Idiopathic \\
\hline Poe $(1989)^{8}$ & 139 & $35 \%$ & $5 \%$ & $26 \%$ & $12 \%$ \\
Irwin $(2006)^{9}$ & 24 & $21 \%$ & $33 \%$ & $33 \%$ & $46 \%$ \\
O'Connell (1994) & 87 & $10 \%$ & $32 \%$ & $34 \%$ & $27 \%$ \\
McGarvey $(1998)^{10}$ & 43 & $23 \%$ & $19 \%$ & $21 \%$ & $19 \%$ \\
Birring $(2004)^{11}$ & 236 & $24 \%$ & $15 \%$ & $12 \%$ & $26 \%$ \\
Nimi $(2005)^{12}$ & 50 & $26 \%$ & $10 \%$ & $7 \%$ & $40 \%$ \\
Shirarata $(2005)^{13}$ & 55 & $42 \%$ & 0 & $73 \%$ & $17 \%$ \\
\hline
\end{tabular}

$A C=$ atopic cough. $C B=$ chronic bronchitis. $C V A=$ cough-variant asthma. EB=eosinophilic bronchitis. GER=gastroesophageal reflux. UACS=upper airways cough syndrome. (Adapted from Chung, Kian Fan, e lan D Pavord. Prevalence, pathogenesis, and causes of chronic cough. The Lancet. 2008;371, n. 9621:1364-74)

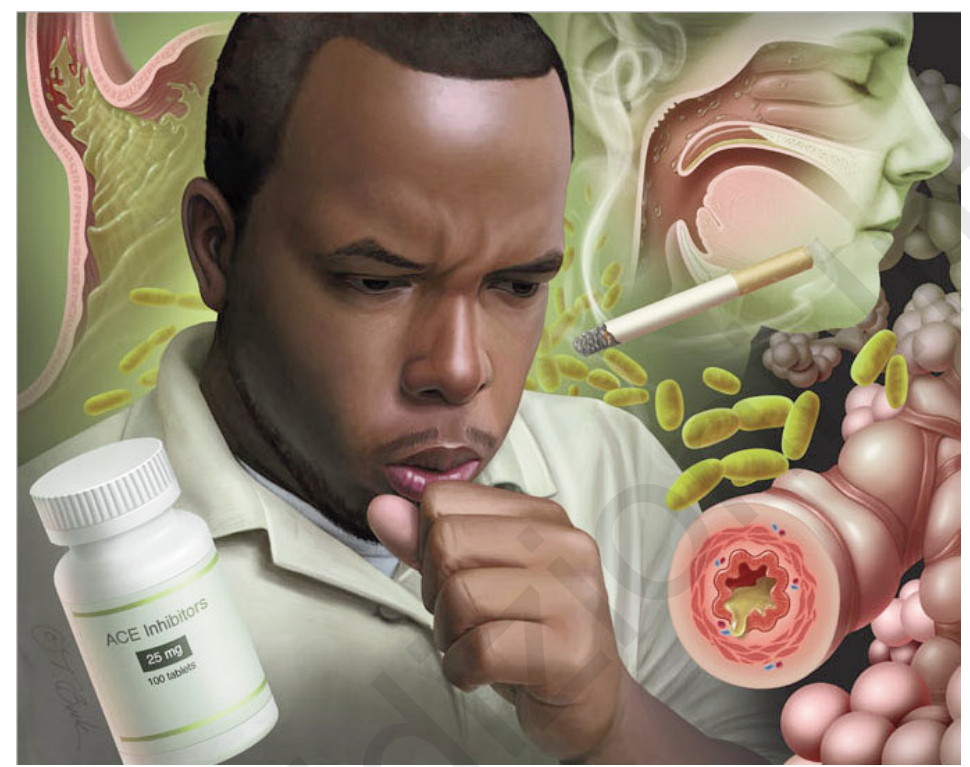

Figure 1 - Chronic cough - A disorder with a number of possible causes.

\section{Asthma}

The diagnosis of chronic cough due to asthma can be made only after the resolution with specific therapy for asthma. Although the identifica-

tion of asthma can be relatively easy when the cough is associated with wheezing and dyspnea, errors can occur both in diagnosis and in the selection of the treatment. Respiratory functional tests with bronchoreversity could disclose an undiagnosed asthma, especially in cough variant asthma (CVA) and reduce incorrect diagnosis of chronic bronchitis in
Lung function test with bronchial reversibility test may disclose an undiagnosed asthma, especially in cough variant asthma. This is important to reduce incorrect diagnosis of chronic bronchitis in asthmatic smokers. asthmatic smokers. Provocative tests are recommended whether physical examination and spirometry are not determinant. Although the empiric therapy is suggested even in its absence, the execution of methacoline inhaled challenge can reduce unnecessary treatments. If in the presence of strong suspects of asthma induced cough, the empirical treatment fails, another course with higher doses should be attempted (18). Nonasthmatic eosinophilic bronchitis (NAEB) is a frequent cause of cough. The association with asthma is limited to the presence of eosinophilic pattern in bronchoalveolar lavage or sputum. Indeed normal bronchial responsiveness and absence of airflow limitation are required for the diagnosis of NAEB (19). The treatment is based on inhaled corticosteroids (ICS) and avoidance strategies for allergens and exposures. A 4 weeks course of ICS usually shows improvements in cough and sputum eosinophilia $(20,21)$. 


\section{Gastroesophageal reflux (GER)}

GER is one of the most common causes of cough and its incidence is constantly increasing. Changes in lifestyle are the first line in suspect of gastroesophageal reflux, but they are rarely effective on cough caused by reflux disease. The $24-\mathrm{h} \mathrm{pH}$ monitoring and impedance measurement are the elective tests to assess the presence of both acid and non-acid reflux diseases $(4<\mathrm{pH}<7)(22,23)$. Chronic cough can be the only sign of acid and non-acid reflux diseases; thus the empiric treatment with proton pump inhibitors (PPI) is recommended even in absence of a clear reflux disease symptomatology (24). However an empiric course of PPI of two weeks is not enough to rule out chronic cough due to GER because of the scarce response of cough (25). Several factors influence the response to PPI treatment as the presence of non-acid reflux, the persistence of neuronal inflammation and disorders of gastroesophageal motility (26). Chronic cough due to nonacid gastroesophageal reflux requires an intensive medical treatment before the symptoms start to improve and cough can last for several months after reflux is suppressed $(27,28)$.

\section{Upper airways cough syndrome}

Upper airways cough syndrome (UACS) is reported as the most common cause of chronic cough (29). In chronic conditions it could be hard to recognize the etiology of the postnasal drip, but chronic sinusitis, recurrent upper airways infections and allergic rhinitis are responsible of most of the cases of UACS. Together with reflux disease, UACS takes advantage of empiric therapy and first generation antihistamines are the recom-

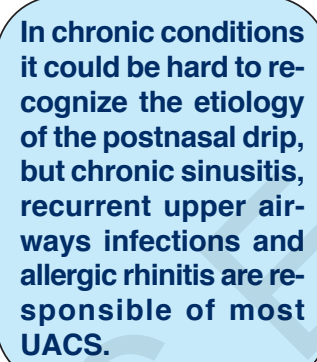
to identificate cases which could benefit from appropriate antihistaminic treatment or even immunotherapy (30). In silent rhinitis, cough can be present alone in absence of other symptoms (headache, discoloured nasal discharge, pain, throat clearing) but endoscopy would reveal the presence of a chronic condition. A morphological study of nasal cavity structures with computed tomography scan is important to evaluate complicated rhinosinusitis (31).

\section{Angiotensin converting enzyme (ACE) inhibitors}

ACE-inhibitor drugs are a frequent cause of dry persistent cough. Although ACE-inhibitors are considerably easy to be identified and removed, their involvement in pathogenesis of cough can be unclear. Recent studies on transient receptor potential (TRP), a subgroup of re- ceptors expressed by neurons of cough reflex, showed that they might be involved in ACE-inhibitors induced cough (32). The mechanism seems to be intrinsic to the ACE-inhibitor effects. The inhibition of angiotensin converting enzyme increases levels of bradykinin and PGE2, which stimulate TRP receptors and the afferent pathway of cough (33). The cough caused by ACE-inhibitors can occur months after the treatment has started and stopping the drug for less than 1 month is not considered enough to appreciate improvements in symptoms (34). Therefore angiotensin converting enzyme inhibitors should be discontinued (if a valuable therapeutic option is available) in patients with chronic cough.

\section{Additional problems}

The patient's compliance to proposed empiric treatments and to behavioural recommendations is often an unpredictable variable (35-37). Sequential and addictive therapies are often required and long treatment courses can break down the patient compliance, especially when the resolution of cough is not prompt. Patients simultaneously presenting two or more of the above mentioned conditions can be a challenge for physicians. An appropriate diagnostic approach often resolves the problematic, but delay of resolution of chronic cough can favour the overlap of GER, asthma and UACS. In these patients the identification of the underlying causes becomes harder and they often refer to a specialist. Two or more causes are present in more than $20 \%$ of consultations (4). There are several mechanisms of interaction between the three most common causes of chronic cough. Chronic rhinosinusitis can predispose to develop asthma (38) and silent gastroesophageal reflux and microaspiration can exacerbate or worsen bronchial hyperreactivity (39). Asthma favours the development of GER through mechanical and neurological effects $(40,41)$. The overlap of these conditions requires an accurate evaluation for each episode which frequently leads to correct diagnosis and treatments $(4,6,10)$. However, even after a comprehensive and specialistic evaluation, some patients still present cough. Among these patients can be found several rare causes of cough. Birring et al. reported tonsillar enlargement as cause of chronic cough and they observed a reduction in cough sensitivity reflex after tonsillectomy (11). Heightened cough reflex can also be observed in patient with autoimmune hypothyroidism, although the pathogenic stimulus is still a matter of debate (42) and in obstructive sleep apnoea syndrome (43). All of the conditions reported above share as common feature the neuronal inflammation, induced by different stimuli.

\section{Cough hypersensitivity syndrome}

Patients with chronic cough presenting vague features of GERD, asthma and UACS frequently receive a diagnosis of idiopathic cough. But if all these conditions share a common pathogenic mechanism, could we re- 


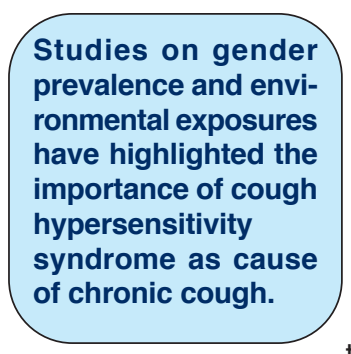

fer to their cough as a disease? Recently several authors introduced the model of "cough hypersensitivity syndrome" in patients with unexplained cough (44-46). Although the clear mechanism is not fully understood yet, transient receptor potential (TRP) are thought to have an important role. TRP is a subgroup of receptors expressed by neurons involved in the cough reflex and their stimulation favours inflammation and neuroinflammation (47). TRP are activated by several stimuli, including low $\mathrm{pH}$, inflammatory mediators, mechanical and irritant insults and temperature (48-51). Indeed, TRP appear to be involved in pathogenesis of cough sustained by asthma, GER, UACS and ACE-inhibitors. Elevated levels of prostaglandines and bradykinin are frequently reported in asthmatic patients $(52,53)$. Bradykinin and PGE2 are potential activators of TRP receptors (33) and their hyperactivation may lead to cough hypersensitivity in asthmatic patients. In gastroesophageal reflux disease, acid and nonacid, there are several findings which suggest the involvement of TRP in the pathogenesis of cough. Acid can induce an abnormal activation of TRP receptors (54) and their activity is increased in presence of inflammation (55). Chronic stimulation induced by acid promotes hyperexpression of TRP and development of cough hypersensitivity, even in the bare of gaseous reflux. In UACS and rhinitis, postnasal drip is not considered the only cause of chronic cough (56); upper airways secretions can assume the role of mechanical stimuli triggering the cough reflex. Studies on animal models demonstrated that cough induced by mechanical stimulation is potentiated by inhalation of capsaicin, a TRP agonist (57). Although the clear cause of hypersensitivity is still under debate, the inflammation associated with rhinosinusitis can be responsible of the increased TRP receptors in those patients (58). Studies on gender prevalence of cough and on environmental exposures have highlighted the importance of cough hypersensitivity syndrome (CHS) as cause of chronic cough. Women with chronic cough show a heightened reflex compared to men, probably due to overexpression of TRPs (59). The exposition both to irritants and common intense odors seem to increase the cough reflex through the afferent pathway activated by TRPs $(60,61)$. As discussed above, cough hypersensitivity is associated to the most common causes of chronic cough and it helps to understand the pathogenesis of the symptom. But can we still refer to cough as a symptom in patients with isolated cough hypersensitivity? Considering hypersensitivity cough syndrome as a disease with its own phenotypes may help in management and treatment. Patients with hypersensitivity cough may present different degrees of symptoms of UACS, GER and asthma, which may represent different phenotypes (62, 63) with their own therapy. However, even after an appropriate treatment the hypersensitivity cough may last longer than the resolution of the other symptoms. Thus the hypersensitivity cough syndrome may be considered as a neuropathic disease sustained by a secondary dysregulation of the cough reflex (46). Moreover, diagnosis of hypersensitivity syndrome prevents physicians to label patients as idiopathic coughers, which is a negative prognostic factor, because a history of persistent cough is often associated with both psychological and functional deterioration (64). Finally a specific disease may deserve a specific treatment. Recent discovers on TRP suggest a more prominent role of the neurological regulation of cough reflex in development of chronic cough and new treatments are starting to show beneficial effects $(65,66)$.

Nowadays an updated approach to chronic cough should consider the role of hypersensitivity as a potential cause of persisting cough, despite the primary trigger may be extinguished. Changing the paradigm from symptom to disease could be a crucial milestone in the management of cough.

\section{References}

1. Najnin N, Sinclair M, Forbes A, Leder K. Community based study to compare the incidence and health services utilization pyramid for gastrointestinal, respiratory and dermal symptoms. BMC health services research. 2012 Jul 23;12(1):211.

2. Dicpinigaitis PV, Colice GL, Goolsby MJ, Rogg GI, Spector SL, Winther B. Acute cough: a diagnostic and therapeutic challenge. Cough. 2009;5:11.

3. Kauffmann F, Varraso R. The epidemiology of cough. Pulm Pharmacol Ther. 2011 Jun;24(3):289-94.

4. Irwin RS, Corrao WM, Pratter MR. Chronic persistent cough in the adult: the spectrum and frequency of causes and successful outcome of specific therapy. Am Rev Respir Dis. 1981 Apr;123(4 Pt 1):4137.

5. Haque RA, Usmani OS, Barnes PJ. Chronic idiopathic cough*: A discrete clinical entity? Chest. 2005 May;127(5):1710-3.

6. Chung KF, Pavord ID. Prevalence, pathogenesis, and causes of chronic cough. The Lancet. $2008 \mathrm{Apr}$ 25;371(9621):1364-74.

7. O'Connell F, Thomas VE, Pride NB, Fuller RW. Capsaicin cough sensitivity decreases with successful treatment of chronic cough. Am J Respir Crit Care Med. 1994 Aug;150(2):374-80.

8. Poe RH, Harder RV, Israel RH, Kallay MC. Chronic persistent cough. Experience in diagnosis and outcome using an anatomic diagnostic protocol. Chest. 1989 Apr;95(4):723-8.

9. Irwin RS, Ownbey R, Cagle PT, Baker S, Fraire AE. Interpreting the histopathology of chronic cough: a prospective, controlled, comparative study. Chest. 2006 Aug;130(2):362-70.

10. McGarvey LPA, Heaney LG, Lawson JT, Johnston BT, Scally CM, Ennis M, et al. Evaluation and outcome of patients with chronic non-productive cough using a comprehensive diagnostic protocol. Thorax. 1998 Sep 1;53(9):738-43. 
11. Birring SS, Passant C, Patel RB, Prudon B, Murty GE, Pavord ID. Chronic tonsillar enlargement and cough: preliminary evidence of a novel and treatable cause of chronic cough. Eur Respir J. 2004 Feb 1;23(2):199-201.

12. Niimi A, Torrego A, Nicholson AG, Cosio BG, Oates TB, Chung KF. Nature of airway inflammation and remodeling in chronic cough. J Allergy Clin Immunol. 2005 Sep;116(3):565-70.

13. Shirahata K, Fujimoto K, Arioka H, Shouda R, Kudo $\mathrm{K}$, Ikeda S. Prevalence and clinical features of cough variant asthma in a general internal medicine outpatient clinic in Japan. Respirology. 2005 Jun;10(3): 354-8.

14. Irwin RS. Unexplained Cough in the Adult. Otolaryngologic Clinics of North America. 2010 Feb;43(1): 167-80.

15. Brignall K, Jayaraman B, Birring S. Quality of Life and Psychosocial Aspects of Cough. Lung. 2008;186 (0):55-8 .

16. Pratter MR, Brightling CE, Boulet LP, Irwin RS. An empiric integrative approach to the management of cough: ACCP evidence-based clinical practice guidelines. Chest. 2006 Jan;129(1 Suppl):222S-231S.

17. Palombini BC, Villanova CA, Araújo E, Gastal OL, Alt DC, Stolz DP, et al. A pathogenic triad in chronic cough: asthma, postnasal drip syndrome, and gastroesophageal reflux disease. Chest. 1999 Aug;116 (2):279-84

18. Dicpinigaitis PV. Chronic cough due to asthma: ACCP evidence-based clinical practice guidelines. Chest. 2006 Jan;129(1 Suppl):75S-79S.

19. Brightling CE, Ward R, Goh KL, Wardlaw AJ, Pavord ID. Eosinophilic Bronchitis Is an Important Cause of Chronic Cough. Am J Respir Crit Care Med. 1999 Aug;160(2):406-10.

20. Brightling CE, Ward R, Wardlaw AJ, Pavord ID. Airway inflammation, airway responsiveness and cough before and after inhaled budesonide in patients with eosinophilic bronchitis. Eur Respir J. 2000 Apr 1;15(4):682-6.

21. Brightling $C E$. Chronic cough due to nonasthmatic eosinophilic bronchitis: ACCP evidence-based clinical practice guidelines. Chest. 2006 Jan;129(1 Suppl):116S-121S.

22. Irwin RS. Chronic cough due to gastroesophageal reflux disease: ACCP evidence-based clinical practice guidelines. Chest. 2006 Jan;129(1 Suppl):80S-94S.

23. Villa N, Vela MF. Impedance-pH testing. Gastroenterol Clin North Am. 2013 Mar;42(1):17-26.

24. Dent J, El-Serag HB, Wallander M-A, Johansson S. Epidemiology of gastro-oesophageal reflux disease: a systematic review. Gut. 2005 May 1;54(5):710-7.

25. Chang AB, Lasserson TJ, Kiljander TO, Connor FL, Gaffney JT, Garske LA. Systematic review and metaanalysis of randomised controlled trials of gastro-oesophageal reflux interventions for chronic cough associated with gastro-oesophageal reflux. BMJ. 2006 Jan 7;332(7532):11-7.

26. Pacheco-Galván A, Hart SP, Morice AH. Relationship between gastro-oesophageal reflux and airway diseases: the airway reflux paradigm. Arch Bronconeu- mol. 2011 Apr;47(4):195-203.

27. Irwin RS, Zawacki JK, Curley FJ, French CL, Hoffman PJ. Chronic Cough as the Sole Presenting Manifestation of Gastroesophageal Reflux. American Review of Respiratory Disease. 1989 Nov;140(5): 1294-300.

28. Irwin RS, Zawacki JK, Wilson MM, French CT, Callery MP. Chronic cough due to gastroesophageal reflux disease*: Failure to resolve despite total/neartotal elimination of esophageal acid. Chest. 2002 Apr 1;121(4):1132-40.

29. Irwin RS, Curley FJ, French CL. Chronic Cough: The Spectrum and Frequency of Causes, Key Components of the Diagnostic Evaluation, and Outcome of Specific Therapy. Am Rev Respir Dis. 1990 Mar 1;141(3):640-7.

30. Pratter MR. Chronic upper airway cough syndrome secondary to rhinosinus diseases (previously referred to as postnasal drip syndrome): ACCP evidence-based clinical practice guidelines. Chest. 2006 Jan;129(1 Suppl):63S-71S.

31. Dykewicz MS, Fineman S, Skoner DP, Nicklas R, Lee $\mathrm{R}$, Blessing-Moore J, et al. Diagnosis and Management of Rhinitis: Complete Guidelines of the Joint Task Force on Practice Parameters in Allergy, Asthma and Immunology. Annals of Allergy, Asthma \& Immunology. 1998 Nov;81(5):478-518.

32. Fox AJ, Lalloo UG, Belvisi MG, Bernareggi M, Chung $\mathrm{KF}$, Barnes PJ. Bradykinin-evoked sensitization of airway sensory nerves: A mechanism for ACE-inhibitor cough. Nature Medicine. 1996 Jul;2(7):814-7.

33. Grace M, Birrell MA, Dubuis E, Maher SA, Belvisi MG. Transient receptor potential channels mediate the tussive response to prostaglandin E2 and bradykinin. Thorax. 2012 Oct 1;67(10):891-900.

34. Dicpinigaitis PV. Angiotensin-converting enzyme inhibitor-induced cough: ACCP evidence-based clinical practice guidelines. Chest. 2006 Jan;129(1 Suppl): 169S-173S.

35. Horne R. Compliance, adherence, and concordance: Implications for asthma treatment. Chest. 2006 Jul;130(1 suppl):65S-72S.

36. Chheda NN, Postma GN. Patient compliance with proton pump inhibitor therapy in an otolaryngology practice. Annals of Otology, Rhinology and Laryngology. 2008;117(9):670-2.

37. Heaney LG, Horne R. Non-adherence in difficult asthma: time to take it seriously. Thorax. 2012 Mar 1;67(3):268-70.

38. Brożek JL, Bousquet J, Baena-Cagnani CE, Bonini S, Canonica GW, Casale TB, et al. Allergic Rhinitis and its Impact on Asthma (ARIA) guidelines: 2010 Revision. Journal of Allergy and Clinical Immunology. 2010 Sep;126(3):466-76.

39. Harding SM, Guzzo MR, Richter JE. The Prevalence of Gastroesophageal Reflux in Asthma Patients without Reflux Symptoms. Am J Respir Crit Care Med. 2000 Jul;162(1):34-9.

40. Harding SM. Gastroesophageal reflux and asthma: Insight into the association. Journal of Allergy and Clinical Immunology. 1999 Aug;104(2):251-9.

41. Zerbib F, Guisset O, Lamouliatte H, Quinton A, 
Galmiche JP, Tunon-de-Lara JM. Effects of Bronchial Obstruction on Lower Esophageal Sphincter Motility and Gastroesophageal Reflux in Patients with Asthma. Am J Respir Crit Care Med. 2002 Nov 1;166(9):1206-11.

42. Birring SS, Patel RB, Parker D, Mckenna S, Hargadon $B$, Monteiro WR, et al. Airway function and markers of airway inflammation in patients with treated hypothyroidism. Thorax. 2005 Mar 1;60(3): 249-53.

43. Faruqi S, Fahim A, Morice AH. Chronic cough and obstructive sleep apnoea: reflux-associated cough hypersensitivity? Eur Respir J. 2012 Oct 1;40(4): 1049-50.

44. Morice AH. Chronic cough hypersensitivity syndrome. Cough. 2013 May 13;9:14.

45. Chung KF. Chronic "cough hypersensitivity syndrome": A more precise label for chronic cough. Pulmonary Pharmacology \& Therapeutics. 2011 Jun; 24(3):267-71.

46. Chung KF, McGarvey L, Mazzone SB. Chronic cough as a neuropathic disorder. The Lancet Respiratory Medicine. 2013 Jul;1(5):414-22.

47. Adcock JJ. TRPV1 receptors in sensitisation of cough and pain reflexes. Pulmonary Pharmacology \& Therapeutics. 2009 Apr;22(2):65-70.

48. Hwang SW, Oh U. Hot channels in airways: pharmacology of the vanilloid receptor. Current Opinion in Pharmacology. 2002 Jun;2(3):235-42.

49. Lin S-Y, Corey DP. TRP channels in mechanosensation. Current Opinion in Neurobiology. 2005 Jun; 15(3):350-7.

50. Morice AH, Geppetti P. Cough · 5: The type 1 vanilloid receptor: a sensory receptor for cough. Thorax. 2004 Mar 1;59(3):257-8.

51. Jordt S-E, Tominaga M, Julius D. Acid potentiation of the capsaicin receptor determined by a key extracellular site. PNAS. 2000 Jul 5;97(14):8134-9.

52. Profita M, Sala A, Bonanno A, Riccobono L, Siena L, Melis MR, et al. Increased prostaglandin E2 concentrations and cyclooxygenase- 2 expression in asthmatic subjects with sputum eosinophilia. Journal of Allergy and Clinical Immunology. 2003 Oct;112(4): 709-16.

53. Ricciardolo FLM, Sabatini F, Sorbello V, Benedetto S, Defilippi I, Petecchia L, et al. Expression of vascular remodelling markers in relation to bradykinin receptors in asthma and COPD. Thorax. 2013 Sep 1;68(9):803-11.

54. Gu Q, Lee L-Y. Airway irritation and cough evoked by acid: from human to ion channel. Current Opinion in Pharmacology. 2011 Jun;11(3):238-47.
55. Banerjee B, Medda BK, Lazarova Z, Bansal N, Shaker R, Sengupta JN. Effect of reflux-induced inflammation on transient receptor potential vanilloid one (TRPV1) expression in primary sensory neurons innervating the oesophagus of rats. Neurogastroenterology \& Motility. 2007 Aug;19(8):681-91.

56. O'Hara J, Jones NS. "Post-nasal drip syndrome": most patients with purulent nasal secretions do not complain of chronic cough. Rhinology. 2006 Dec;44(4):270-3.

57. Plevkova J, Kollarik M, Brozmanova M, Revallo M, Varechova S, Tatar M. Modulation of experimentallyinduced cough by stimulation of nasal mucosa in cats and guinea pigs. Respiratory Physiology \& Neurobiology. 2004 Sep;142(2-3):225-35.

58. Yu L, Xu X, Wang L, Yang Z, Lü H, Quu Z. Capsaicinsensitive cough receptors in lower airway are responsible for cough hypersensitivity in patients with upper airway cough syndrome. Med Sci Monit. 2013;19:1095-101.

59. Kastelik JA, Thompson RH, Aziz I, Ojoo JC, Redington AE, Morice AH. Sex-related Differences in Cough Reflex Sensitivity in Patients with Chronic Cough. Am J Respir Crit Care Med. 2002 Oct;166(7):961-4.

60. Millqvist E. Mechanisms of increased airway sensitivity to occupational chemicals and odors. Current Opinion in Allergy \& Clinical Immunology. 2008 Apr;8(2):135-9.

61. Millqvist E, Ternesten-Hasséus E, Bende M. Inhaled ethanol potentiates the cough response to capsaicin in patients with airway sensory hyperreactivity. Pulmonary Pharmacology \& Therapeutics. 2008 Oct; 21(5):794-7.

62. Morice AH, Faruqi S, Wright CE, Thompson R, Bland JM. Cough Hypersensitivity Syndrome: A Distinct Clinical Entity. Lung. 2011 Feb 1;189(1):73-9.

63. Morice AH, Millqvist E, Belvisi MG, Bieksiene K, Birring SS, Chung KF, et al. Expert opinion on the cough hypersensitivity syndrome in respiratory medicine. Eur Respir J. 2014 Aug 19.

64. Yousaf N, Montinero W, Birring SS, Pavord ID. The long term outcome of patients with unexplained chronic cough. Respir Med. 2013 Mar;107(3):408-12.

65. Kerkhove CV de, Goeminne PC, Bleyenbergh PV, Dupont LJ. A cohort description and analysis of the effect of gabapentin on idiopathic. Cough. $2012 \mathrm{Nov}$ $1 ; 8(1): 9$.

66. Ryan NM, Birring SS, Gibson PG. Gabapentin for refractory chronic cough: a randomised, double-blind, placebo-controlled trial. The Lancet. 2012 Nov 9;380(9853):1583-9. 